\title{
Tobacco use patterns and tobacco-related awareness in medical students of Delhi
}

\author{
C. Vankhuma ${ }^{\mathrm{a}, \mathrm{b}}$, Saurav Basu ${ }^{\mathrm{b}, *}$, Nandini Sharma ${ }^{\mathrm{b}}$, Shiv Kumar ${ }^{\mathrm{c}}$ \\ ${ }^{a}$ Mizoram Institute of Medical Education and Research, Falkawn, Mizoram, India \\ ${ }^{\mathrm{b}}$ Dept. of Community Medicine, Maulana Azad Medical College, New Delhi, India \\ ${ }^{c}$ ICMR - National Institute of Medical Statistics, Ministry of Health \& Family Welfare, Government of India, India
}

\section{A R T I C L E I N F O}

\section{Keywords:}

Medical students

Tobacco

Smoking

COTPA

India

\begin{abstract}
A B S T R A C T
Background: Tobacco use is globally one of the leading preventable causes of premature death, disease, and disability. Tobacco use among health professionals is a key interest domain in the area of tobacco-related surveillance since physicians have a pivotal role in tobacco cessation.

The objectives of this study were to determine the prevalence of tobacco use among the undergraduate male medical students and assess their awareness of anti-smoking legislation in India.

Material and methods: We conducted a cross-sectional study among male undergraduate medical (M.B.B.S) students at a premier medical college in New Delhi, India during Jan-Dec' 2015. A total of 302 students completed the self-administered questionnaire. We analyzed the data on SPSS 17.

Results: The prevalence of tobacco (cigarette) smoking in medical students was 9.3\%. There were 203 (67.2\%) students aged below 20 years. Tobacco smoking in the students increased with age and professional year indicating initiation into smoking during college-life. Tobacco use was also significantly higher in the students living in hostels compared to those living with their families $(\mathrm{p}=0.004)$. Ninety-four $(31.1 \%)$ students were unaware that smoking causes lung cancer and 159 (52.6\%) students did not consider smoking as a causal risk factor for coronary heart disease.

A total of $205(67.9 \%)$ students were aware of the existence of a tobacco control law in India and $258(85.4 \%)$ had knowledge of the ban on smoking in public places.

Conclusion: Tobacco usage and the gaps in awareness of its harmful effects among medical students represents a major health concern.
\end{abstract}

\section{Introduction}

Tobacco use is globally one of the leading preventable causes of premature death, disease, and disability. ${ }^{1}$ According to the World Health Organization (WHO), tobacco use kills more than seven people annually. More than $80 \%$ of the global burden of deaths attributable to tobacco use occur in developing world countries. ${ }^{2}$ In India, tobacco use is attributed towards causing a million deaths each year. ${ }^{3}$ According to the National Family Health Survey (2015-16), 43\% of Indian men used some form of tobacco; smokeless tobacco (15\%), cigarette smoking (14\%), bidis (13\%), others (1\%). Tobacco use among women was much lower (7\%) and most of it comprised of smokeless tobacco forms. ${ }^{4} \mathrm{~A}$ modest declined trend in tobacco smoking has been observed in India ${ }^{5}$ which perhaps reflects improved compliance to the Cigarettes and Other Tobacco Products Act (COTPA), 2003 that prohibits smoking in public places, sale of tobacco products to minors, promotional advertisements (direct and indirect) and regulates health warnings on tobacco packs. ${ }^{6}$

The National Tobacco Control Programme (NTCP) of India has the objective of bringing greater awareness about the harmful effects of tobacco use and tobacco control laws through mass media, public awareness campaigns, etc. ${ }^{7}$ Physicians have a pivotal role in tobacco cessation by educating, motivating and offering help to their patients in quitting tobacco and influencing the development of healthy public policy. Furthermore, it is well-established that smoking rates register a decline in physicians before their reduction in the general population as they are role models for society. ${ }^{8}$ Tobacco use among health professionals is therefore of key interest in the area of tobacco-related surveillance. Medical students comprise a numerically small but crucial and relevant demographic whose smoking patterns can indicate the

\footnotetext{
* Corresponding author. Dept. of Community Medicine, Maulana Azad Medical College, Bahadur Shah Zafar Marg, New Delhi, 110002, India.

E-mail address: Saurav.basu1983@gmail.com (S. Basu).
} 
extent of social acceptability and predict future trends of smoking in communities.

The objectives of this study were to determine the prevalence of tobacco use amongst the undergraduate male medical students and to assess their awareness of the anti-smoking legislation in India.

\section{Material and methods}

We conducted a cross-sectional study among undergraduate medical (M.B.B.S) students at a premier medical college in New Delhi, India during Jan-Dec' 2015. The M.B.B.S course is essential to secure a license to practice medicine and surgery in India and is of five and a half years duration, inclusive of a year of medical internship. Students belong to three professional cohorts; first professional (1 year), second professional (1 and half years) and third professional (2 years).

In our study, all the adult male undergraduate students of the college were eligible for inclusion. We excluded female students, medical interns and those male students who could not be contacted despite three attempts. We collected data using a self-administered questionnaire. A total of 349 of the 594 male undergraduate students could be contacted during the study period. We also excluded 47 questionnaires which were incomplete, so the net sample size of the study was 302.

We used a closed-ended questionnaire in English for data collection. The questionnaire was based on validated instruments, i.e., Global Health Professional Tobacco Survey (GHPTS) questionnaires and the GATS (India) questionnaires. ${ }^{9,10}$

The study group was also assessed about their knowledge regarding the existence of the tobacco control act (if any) in India. They were also asked to share their awareness on the Act based on the four major provisions of the COTPA regarding the ban on smoking in public places, the penalty for violation, the age limit for prohibition for buying and selling tobacco and the ban on advertisement of tobacco products in India.

Statistical Analysis: Data was analyzed using SPSS (Statistics for Windows, SPSS Inc. Chicago, IL Version 17). Categorical data were expressed in frequency and proportion. The significance of the difference between the proportions was assessed by the Chi-square test or the Fischer exact test. A P value $<0.05$ was considered statistically significant.

Compliance with ethical standards: The study was approved by the Institutional Ethics Committee of the Medical College. Written and informed consent was taken from all study participants.

\section{Results}

A total of $203(67.2 \%)$ students were aged below 20 years. There were $111(36.8 \%)$ students from the first professional year, $113(37.4 \%)$ from the second professional year and 78 (25.8) from the third professional year. A total of 148 (49\%) students were accommodated in the college hostels while others commuted from home and usually stayed with family.

\subsection{Tobacco use}

The prevalence of tobacco smoking in medical students was $9.3 \%$. All the tobacco users $(n=28)$ reported cigarette smoking. Moreover, there were two bidi smokers, one hookah user, one shisha user, and two smokeless tobacco users. Tobacco use amongst the students increased with age and professional year indicating initiation into smoking during college-life. Students living in hostels were more likely to be tobacco users compared to those staying with family (Table 1).

Tobacco use behavior in the students is reported in Table 2. Amongst the tobacco users $(\mathrm{N}=28)$, a total of $7(25 \%)$ students were using tobacco for more than five years, and 2 (7.2\%) students were consuming tobacco products more than five times a day.
Table 1

Distribution of tobacco use and sociodemographic characteristics in medical students of Delhi, India $(\mathrm{N}=302)$.

\begin{tabular}{|c|c|c|c|c|c|}
\hline Variable & Total & $\begin{array}{l}\text { Tobacco user } \\
\text { n (\%) }\end{array}$ & $\begin{array}{l}\text { Tobacco non- } \\
\text { user n (\%) }\end{array}$ & $\begin{array}{l}\text { Chi } \\
\text { square, d.f }\end{array}$ & 'P' value \\
\hline \multicolumn{6}{|l|}{ Age (in Years) } \\
\hline $18-20$ & 203 & $10(4.9)$ & $193(95.1)$ & & $\mathrm{P}<0.001$ \\
\hline$\geq 21$ & 99 & $18(18.2)$ & $81(81.8)$ & $13.9(1)$ & \\
\hline \multicolumn{6}{|c|}{ Professional year } \\
\hline First & 111 & $4(3.6)$ & 107 (96.4) & & $P=0.009$ \\
\hline Second & 113 & $11(9.7)$ & $102(90.3)$ & & \\
\hline Third & 78 & $13(16.6)$ & $65(83.3)$ & $9.3(2)$ & \\
\hline \multicolumn{6}{|c|}{ Hostel accommodation } \\
\hline Hosteller & 148 & $21(14.2)$ & $127(85.8)$ & & $P=0.004$ \\
\hline Non-Hosteller & 154 & $7(4.5)$ & 147 (95.5) & $8.3(1)$ & \\
\hline \multicolumn{6}{|l|}{ SES } \\
\hline Class I & 247 & $25(10.1)$ & $222(89.9)$ & & $P=0.44$ \\
\hline Class II-V & 55 & $3(5.5)$ & $52(94.5)$ & $1.1(1)$ & \\
\hline
\end{tabular}

Table 2

Distribution of tobacco use behavioral patterns in medical students of Delhi, India $(\mathrm{N}=28)$.

\begin{tabular}{lcc}
\hline Characteristic & Number & Percentage \\
\hline How long have you been using tobacco products? & \\
Less than 5 years & 21 & 75 \\
5 years or more & 7 & 25 \\
How many cigarette/bidi/tobacco pouch do you consume in a day? & 92.7 \\
Less than 5 times & 26 & 7.2 \\
Equal or More than 5 times & 2 & \\
Have you ever tried to quit using tobacco? & 64.2 \\
Yes & 18 & 35.8 \\
No & 10 & 28.6 \\
What has the health warnings against cigarette smoking made you feel like? \\
Quitting & 8 & 17.8 \\
Cutting down use & 5 & 53.6 \\
No effect & 15 & \\
\end{tabular}

\subsection{Awareness of the harmful effects of tobacco}

The students reported sources of health information on the harmful use of tobacco as mass media 172 (57\%), schools/college curriculum 87 (29\%) and friends/family 76 (25\%).

The students reported the following harmful effects of tobacco consumption: respiratory system-related disorders 238 (78.8\%), lung cancer 208 (68.8\%) and coronary heart disease 142 (47.3\%) (Table 3). Students in the third professional year had better awareness compared to their junior cohorts ( $\mathrm{p}<0.05$ ).

The student' awareness of the harmful effects of second-hand smoke on children, pregnant women and adults is reported in Table 4. A total of $21(75 \%)$ tobacco users $(n=28)$ believed it was injurious to health while the rest did not express any opinion. Amongst the non-tobacco users ( $n=274), 257(93.8 \%)$ considered tobacco use harmful to health and well-being. Furthermore, 158 (52.3\%) students regarded second hand smoking more harmful, $112(37 \%)$ as equally harmful and 32 $(10.7 \%)$ less or not harmful compared to first-hand smoking.

\subsection{Awareness of legislation against smoking in public places}

A total of $205(67.9 \%)$ students were aware of the existence of a tobacco control law in India and 258 (85.4\%) were aware of the ban on smoking in public places. Awareness regarding special provisions of the COTPA Act, 2003 in India is reported in Table 5. The recognition of the prohibition of smoking on the campus of educational institutional was present in 265 (87.7\%) students (Fig. 1).

Most students reported observing incidents on the campus which violated the COTPA. Shops selling tobacco in the vicinity of the college was reported by 144 (44.4\%), the absence of signboards prohibiting the 
Table 3

Distribution of awareness in medical students of tobacco related health, Delhi, India $(\mathrm{N}=302)$.

\begin{tabular}{|c|c|c|c|}
\hline Characteristic & First professional students $(\mathrm{n}=111) \mathrm{n}(\%)$ & Second professional students $(\mathrm{n}=113) \mathrm{n}(\%)$ & Third professional students $(\mathrm{n}=88) \mathrm{n}(\%)$ \\
\hline Respiratory problems & $87(78.4)$ & $84(74.3)$ & $64(72.7)$ \\
\hline Coronary Heart disease & $47(42.3)$ & $44(38.9)$ & $52(59)$ \\
\hline Oral cancer & $73(65.8)$ & $76(67.2)$ & $62(70.4)$ \\
\hline Lung cancer & $69(62.2)$ & $78(69)$ & $61(69.3)$ \\
\hline Gastric cancer & $35(31.5)$ & $41(36.3)$ & $38(43.2)$ \\
\hline
\end{tabular}

Table 4

Distribution of awareness in medical students of harmful effects of second hand smoke, Delhi, India $(\mathrm{N}=302)$.

\begin{tabular}{lll}
\hline Harmful effects of second hand smoke & Aware n (\%) & Not aware n (\%) \\
\hline $\begin{array}{ll}\text { On Children } \\
\text { Respiratory system related }\end{array}$ & $229(75.8)$ & $73(24.2)$ \\
Heart Disease & $134(44.3)$ & $168(55.7)$ \\
Cancer & $120(39.7)$ & $182(60.3)$ \\
On Adults & & \\
Respiratory system related & $188(62.3)$ & $114(37.7)$ \\
Heart Disease & $122(40.4)$ & $180(59.6)$ \\
Cancer & $159(52.6)$ & $143(47.4)$ \\
On Pregnant women & & \\
Hypertension & $131(43.4)$ & $171(56.6)$ \\
Abortions & $174(57.6)$ & $128(42.4)$ \\
Risk of LBW baby & $180(59.6)$ & $122(40.4)$ \\
\hline
\end{tabular}

sale of tobacco in and near the campus by 147 (47\%) and lack of information of nodal officer for reporting offenders by 241 (79.8\%) students.

\section{Discussion}

The physician has a principal obligation to fulfill at-least three critical components of the WHO- MPOWER strategy for country-level implementation of effective interventions for tobacco-demand reduction. These include; protecting people from tobacco smoke, offering help to people to quit tobacco use and warning everyone about the dangers of tobacco. ${ }^{11}$ The present study found tobacco use prevalence in $9.3 \%$ and high use ( $\geq 5$ cigarette/day) in two medical undergraduate students. There were significant gaps in the awareness of the harmful effects of tobacco use among the students. Nearly one-third of the students were unaware that smoking causes lung cancer and more than half did not consider smoking as a causal risk factor for developing heart disease. One in ten students believed second-hand smoking was less or not harmful compared to first-hand smoking.

The Global Youth tobacco survey 2009 had revealed that nearly $15 \%$ of adolescents in India aged from 13 to 15 years were tobacco users which is higher than our study estimates. ${ }^{12}$ Nevertheless, considerable variation has been observed in tobacco use prevalence amongst medical students. A study in a different medical college in Delhi in 2011 had found $27.1 \%$ tobacco smoking prevalence amongst male students. ${ }^{13}$ Another survey from coastal South India reported $22.4 \%$ current smoking prevalence in medical students. ${ }^{14}$

A study from Pakistan among health professionals found $10.8 \%$ ( $n=391$ ) participants were current smokers, and $26.7 \%$ were cigarette

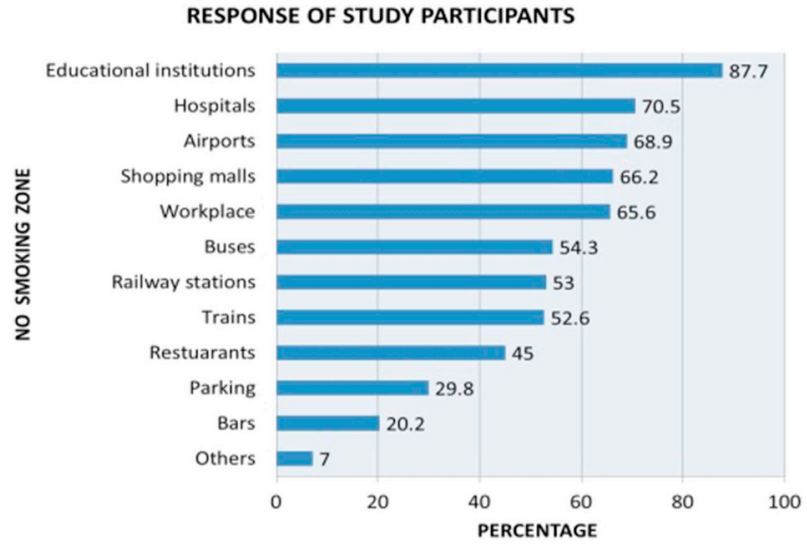

Fig. 1. Awareness of medical students of the No-Smoking zones.

experimenters. ${ }^{15}$ Candido et al. (2018) conducted a narrative review and found tobacco to be the second most common drug used by Brazilian male medical students despite their understanding of its harmful effects. $^{16}$

Our study found that senior students and students residing in the hostel were more likely to be tobacco users which is consistent with the findings of previous studies indicating the detrimental role of peer pressure. We also observed suboptimal awareness of the harmful effects of tobacco use and legislation against a ban on smoking in public places (COTPA Act). The awareness improved in the senior professional students, probably due to the increased curricular coverage of the harmful effects of tobacco smoking and benefits of cessation but the overall knowledge was still unsatisfactory.

Based on our study findings, we recommend interactive educational sessions with proven efficacy for improving the awareness of the harmful effects of tobacco use and lowering the risk of tobacco addiction in college students. ${ }^{17}$ These sessions should be included as part of the undergraduate orientation program at the time of admission into college to help students resist peer pressure and abstain from experimenting with tobacco use. Furthermore, strict implementation of the COTPA act for attaining a complete ban on tobacco smoking and preferably, tobacco use in all forms in the college campuses and their declaration as tobacco-free zones can help sensitize students against tobacco use and experimentation.

A limitation of the present study was that it included a lesser representation of students from the third professional year who were also more likely to be smokers. This was due to logistical challenges and was not due to non-response. Moreover, the use of self-reported instruments

Table 5

Distribution of awareness of tobacco control laws in medical students, Delhi, India $(\mathrm{N}=302)$.

\begin{tabular}{lll}
\hline Aspect of law & Awareness present n (\%) & Awareness absent n (\%) \\
\hline Existence of tobacco control law & $205(67.9)$ & $97(32.1)$ \\
Ban on sale of tobacco products to minors & $233(77.1)$ & $69(22.9)$ \\
Legal age limit for purchase of tobacco products & $112(37)$ & $90(63)$ \\
Mandatory display of health specific warnings & $177(58.6)$ & $125(41.4)$ \\
Ban of smoking in public places & $258(85.4)$ & $44(14.6)$ \\
\hline
\end{tabular}


can be an unreliable means for estimating tobacco use as the participants can be inclined towards underreporting tobacco use or its magnitude due to the perceived social disapproval. The prevalence of tobacco use is therefore likely to be underreported in our study.

\section{Conclusion}

Tobacco usage, inadequate knowledge of the harmful effects of tobacco and poor awareness of anti-smoking legislation in medical students, represents a significant public health challenge. Medical students are future physicians who will with time get tasked with combating tobacco use in the general population. Physicians have well-established roles for the promotion of tobacco cessation in their patients through counseling which is more likely to be successful if they do not themselves smoke. ${ }^{18}$ Moreover, there is evidence that current smokers are less likely to support the strict implementation of a universal ban on smoking in public places. Our study findings show that nearly one in ten medical students were current smokers with a higher prevalence among senior students. This poses an enormous threat to the goal of achieving a global tobacco-free world. The effectiveness of educational interventions initiated early in college life in diminishing the initiation of tobacco use and in achieving cessation need to be explored in future studies.

\section{Sources of funding}

Nil.

\section{Conflicts of interest}

None.

\section{References}

1. Mishra GA, Pimple SA, Shastri SS. An overview of the tobacco problem in India. Indian J Med Paediatr Oncol. 2012;33(3):139-145.

2. WHO. Tobacco Fact Sheet. [Internet]. 2018; 2018. [Cited 23 November 2018] Available from:. http://www.who.int/news-room/fact-sheets/detail/tobacco.

3. Jha P, Jacob B, Gajalakshmi V, et al. A nationally representative case-control study of smoking and death in India. N Engl J Med. 2008;358(11):1137-1147.

4. International Institute for Population Sciences (IIPS) and ICF. National Family Health Survey (NFHS-4), 2015-16: India. Mumbai: IIPS; 2017.

5. Mishra S, Joseph RA, Gupta PC, et al. Trends in bidi and cigarette smoking in India from 1998 to 2015, by age, gender and education. [Internet]. BMJ Glob Health. 2016. [Cited 23 November 2018];1(1):e000005. Available from:. https://doi.org/10.1136/ bmjgh-2015-000005.

6. Government of India. The Cigarettes and Other Tobacco Products (Prohibition of Advertisement and Regulation of Trade and Commerce, Production, Supply and Distribution) Act. 2003; 2003. [Internet]. 2003 [Cited 23 November 2018] Available from:. https://www.tobaccocontrollaws.org/files/live/India/India\%20-\%20COTPA. pdf.

7. Government of India. National Tobacco Control Program. . [Internet]. [Cited 23 November 2018] Available from:. https://www.nhp.gov.in/National-TobaccoControl-Programme1_pg.

8. Smith D, Leggat P. An international review of tobacco smoking in the medical profession: 1974-2004. [Internet]. BMC Public Health. 2007. [Cited 23 November 2018];7(147):115. Available from:. https://doi.org/10.1186/1471-2458-7-115.

9. GTSS Collaborative Group. Tobacco use and cessation counselling: global health professionals survey pilot study, 10 countries. 2006 Tobac Contr. 2005;15 Suppl 2(Suppl 2):ii31-i34.

10. Global Adult Tobacco Survey Colloborative Group. Tobacco Questions for Surveys: A Subset of Key Questions from the Global Adult Tobacco Survey (GATS). second ed. Atlanta, GA: Centers for Disease Control and Prevention; 2011.

11. WHO. WHO Report on the Global Tobacco Epidemic: Warning about the Dangers of Tobacco. Geneva: WHO; 2011.

12. WHO. Global Youth Tobacco Survey. Fact Sheet: India (Ages 13-15). . [Internet]. WHO [Cited 23 November 2018] Available from:. http://www.who.int/fctc/ reporting/Annexoneindia.pdf.

13. Aggarwal S, Sharma V, Randhawa H, Singh H. Knowledge, attitude and prevalence of use of tobacco among medical students in India: a single center cross sectional study. Ann Trop Med Public Health. 2012;5:327-329.

14. Ganesh Kumar S, Subba SH, Unnikrishna B, Jain A, Badiger S. Prevalence and factor associated with current smoking among medical students in coastal South India. Kathmandu Univ Med J. 2011;9(36):233-237.

15. Aslam S, Mehboob B, Zaheer S, Shafique K. Awareness and Support for Anti-tobacco Policies Among Health Professional Students in Pakistan: Findings from the Global Health Professional Students Survey, 2011. Subst Abuse Treat Prev Policy. [Internet]. 2015; 2015. [Cited 23 November 2018];10:7. Available from:. https://doi.org/10.1186/ s13011-015-0001-x.

16. Candido FJ, Souza R, Stumpf MA, et al. The use of drugs and medical students: a literature review. Rev Assoc Med Bras. 2018;64(5):462-468.

17. Mahmood N, Othman S, Al-Tawil N, Al-Hadithi T. Impact of an education intervention on knowledge of high school students concerning substance use in Kurdistan Region-Iraq: a quasi-experimental study. PLoS One. 2018;13(10):e0206063. Available from: https://doi.org/10.1371/journal.pone.0206063.

18. Nett LM. The physician's role in smoking cessation: a present and future agenda. Chest. 1990;97(Suppl 2):28S-32S. 